\title{
Numeric Conversion
}

National Cancer Institute

\section{Source}

National Cancer Institute. Numeric Conversion. NCI Thesaurus. Code C74552.

The process by which a value is assigned to represent another set of values for ease of evaluation within a particular process. 